\title{
Bem-Estar Subjetivo, Educação, Inteligência e Religião
}

\author{
José Aparecido da Silva ${ }^{1}$ \\ Departamento de Psicologia da Universidade de São Paulo, \\ Ribeirão Preto, Brasil \\ Rosemary Conceição dos Santos \\ Faculdade de Filosofia, Letras e Ciências Humanas da Universidade de São Paulo, \\ São Paulo, Brasil
}

Este comentário refere-se ao artigo de Meisenberg, Rindermann, Patel, e Woodley (2012) e ao debate subsequente (Dutton, 2013; Meisenberg, 2013).

Dutton (2013) e Meisenberg e colaboradores (Meisenberg, 2013; Meisenberg, Rindermann, Patel, \& Woodley, 2012) têm, neste periódico, discutido a robusta e negativa relação entre inteligência e crenças religiosas nos Estados Unidos e na Europa, bem como, destacado o papel mediador da educação, tipos de crenças religiosas, fertilidade e fatores de personalidade, aspectos estes que, na literatura pertinente, fomentam inúmeras controvérsias e interesses teóricos. Interessante também são as prováveis causas aludidas visando a explicação da elevação de tais correlações ao longo do desenvolvimento da civilização.

Não obstante tal importância da inteligência e sua relação com a religião, cumpre apontar, também, o papel da religiosidade nas estimativas individuais ou agregadas do bem-estar subjetivo.

\section{Paradoxo da Religião}

Inúmeros estudos têm demonstrado que pessoas religiosas registram, em média, um maior grau de bem-estar subjetivo, bem como, menor número de determinadas patologias sociais, dentre as quais os abusos domésticos, por exemplo. Levantamentos realizados entre 1972 a 2008, nos Estados Unidos, revelaram que a porcentagem de pessoas indicando que são muito felizes variou de $26 \%$, entre aqueles que nunca atendem aos serviços religiosos, a $48 \%$, entre aqueles que os atendem mais que uma vez semanalmente. Não obstante, as pessoas que vivem em nações mais ricas tendem a deixar a religião tradicional ou não têm qualquer afiliação religiosa específica, sendo tal fuga mais substancial em nações do norte da Europa e em outras nações economicamente mais afluentes.

A título de exemplo, no jornal diário $O E s$ tado de São Paulo (Leal, 2011) relata-se que a proporção de católicos, em relação às demais religiões, tem apresentado baixa recorde. A reportagem mostra um novo mapa das religiões no qual a proporção de católicos, em 2009, foi a menor registrada em quase 140 anos de pesquisas estatísticas no país. Em outras palavras, embora continue maioria, a população católica chegou a $68 \%$ do total de brasileiros, o equivalente a 130 milhões de pessoas, mas, pela primeira vez neste mesmo país, tal proporção foi menor que $70 \%$. Dados similares também revelaram uma estagnação do número de evangélicos pentecostais que, nos anos 90, apresentaram grande crescimento, assim como, um elevado crescimento do número dos que se dizem sem religião específica.

Pergunta-se, "Por que as pessoas estão deixando a religião tradicional, em nações onde a liberdade religiosa é alta, se essa mesma religião é associada a benefícios como, por exem-

Endereço para correspondência: Departamento de Psicologia, Faculdade de Filosofia, Ciências e Letras de Ribeirão Preto, Universidade de São Paulo, Av. Bandeirantes, 3900, Campus da USP-RP, Ribeirão Preto, SP, Brasil, CEP 14040-901. E-mail: jadsilva@ffclrp.usp.br. 
plo, bem-estar subjetivo mais elevado?". Acerca disso, alguns teóricos supõem que o declínio na religiosidade é associado com o crescimento econômico, ou seja, que a religião ajude as pessoas a lidarem com circunstâncias difíceis, sendo mais benéfica quanto mais complexo, e difícil, é o contexto de vida das pessoas. Nações economicamente desenvolvidas, em média, são superiores em alcançarem as necessidades básicas previamente pretendidas, como educação, segurança e longevidade, por exemplo.

Neste mesmo contexto, tais nações têm também melhor infraestrutura que outras protetoras contra desastres naturais e doenças epidêmicas. Assim, em nações economicamente desenvolvidas, supostamente, as pessoas são mais hábeis em alcançar os mais elevados indicadores de bemestar subjetivo sem a ajuda da religião organizada. Contrastando, quando as pessoas se deparam mais frequentemente com a fome, doenças, crimes e educação não qualitativa, as quais são relativamente mais descontroladas, e prevalentes, em sociedades pobres, a religião pode, talvez, fazer uma contribuição maior para o bem-estar. Nestas nações, religiosidade, usualmente, é associada com maior suporte social, respeito, propósito ou significado na vida.

Considerando especificamente a relação entre religiosidade e bem-estar subjetivo das diferentes nações (escores agregados), religião correlaciona-se em -0,48 com avaliações da vida, a qual varia de 3,0 no Togo, onde $88 \%$ disseram que religião é importante em sua vida diária, a 7,9 na Dinamarca, onde 19\% afirmaram que religião é importante. No nível individual, após controlar circunstâncias negativas, as pessoas religiosas tendem a ter indicadores de bem-estar subjetivos mais elevados, mas os efeitos benéficos são maiores em nações mais difíceis.

Assim considerando, a associação de religiosidade com bem-estar subjetivo pode depender de duas condições, a saber: se uma sociedade enfrenta condições de vida mais difíceis ou se é altamente religiosa. Em sociedades menos religiosas, com circunstâncias relativamente favoráveis, o bem-estar subjetivo médio elevado é atingido pela maioria das pessoas, independente da religiosidade. Nestas sociedades, os benefí- cios da religiosidade para o bem-estar subjetivo são atenuados uma vez que os indivíduos não religiosos têm níveis elevados de suportes sociais e respeito, os quais já lhes garantem o mesmo. Parece, então, que, em muitas circunstâncias sociais desafiadoras, a religiosidade agrega respeito, suporte social e propósito e significado na vida, os quais, por sua vez, são associados com níveis mais elevados de bem-estar subjetivo.

\section{Felicidade e Religião}

Sendo salientes as conexões entre religião e saúde mental, é a religião, como suposta por Freud, corrosiva para a felicidade, isto pelo fato da mesma criar uma neurose obsessiva que entalha culpa, sexualidade reprimida e emoções suprimidas, associando-a a satisfação e prazer. Evidências acumuladas revelam que algumas formas de experiências religiosas se correlacionam com preconceitos e culpa, mas, em geral, a religiosidade ativa é mais associada com vários critérios de saúde mental. Pessoas ativamente religiosas são bem menos prováveis de tornaremse delinquentes, viciados em drogas e álcool, divorciarem-se e cometerem suicídio do que as não religiosas.

Ademais, dados revelam que pessoas ativamente religiosas tendem a ser fisicamente mais saudáveis e viverem mais longamente, também. Por sua vez, outras pesquisas têm revelado estreita correlação entre fé e capacidade de enfrentamento de crises que ocorram ao longo de suas vidas. Por exemplo, comparadas com viúvas religiosamente inativas, aquelas recentemente enviuvadas que, usualmente, participam de cultos religiosos, registram uma maior satisfação e alegria em suas vidas. Também, entre as mães de crianças com dificuldades evolutivas e cognitivas, aquelas com profunda fé religiosa têm se mostrado menos vulneráveis à depressão. Pessoas de fé também tendem a reter, ou a recuperar, uma maior felicidade após passarem por divórcio, desemprego, doença grave ou sofrimento intenso. Para as pessoas, os dois melhores preditores da satisfação com a vida, na maturidade, têm sido saúde e religiosidade.

Em um levantamento realizado em várias nações, pessoas religiosamente ativas também 
registram, de alguma forma, níveis mais altos de felicidade. Por exemplo, aqueles que tiveram escores mais elevados, numa escala de comprometimento espiritual, foram duas vezes mais prováveis que aqueles com pontuações menores para se declararem muito felizes. Outros levantamentos revelam níveis mais elevados de pessoas muito felizes dentre aqueles que se sentem "extremamente próximos a Deus" (41\%), bem como, daqueles que expressam de "algum modo próximo" à religião (29\%) ou "não próximo, ou descrente, da mesma" (23\%).

Interessante observar, também, que há uma estreita correlação entre felicidade e medidas comportamentais de religiosidade. De fato, dados revelam que $47 \%$ das pessoas que frequentam cultos religiosos se consideram muito felizes, enquanto que 39\% que atendem semanalmente, $35 \%$ que atendem quase toda semana, $31 \%$ que frequentam mensalmente e $28 \%$ daqueles que atendem menos que mensalmente, registram que são muito felizes.

Procurando explicar estas associações entre fé e bem-estar subjetivo, pesquisadores têm considerado várias possibilidades. Uma delas reside no fato de que a fé comunitária fornece suporte social, haja vista que religião usualmente é praticada coletivamente. Outra explicação para a correlação entre fé e bem-estar subjetivo está no sentido do significado e propósito que muitas pessoas derivam de sua fé. Esta hipótese entende que a religião satisfaz a mais fundamental de todas as necessidades humanas, a saber, a necessidade de conhecer que nós temos importância, que nossas vidas significam alguma coisa, bem como, contam como alguma coisa mais que simplesmente um pequeno ponto no universo. $\mathrm{Na}$ realidade, as pessoas têm esperança de que a fé sirva como amortecedor ou mesmo redutor do sofrimento e do enfrentamento denominado "o terror resultante de nossa consciência de vulnerabilidade e morte".

Ou seja, procurando compreender "quem" é feliz e "por que" nós podemos ajudar as pessoas a repensarem suas prioridades e a entenderem melhor como construir um mundo enriquecedor do bem-estar humano.

\section{Educação e Crenças Religiosas}

Entretanto, evidências de que as medidas de religiosidade são negativamente relacionadas com inteligência também existem. De fato, após a publicação do livro "Deus, um Delírio", de Dawkins (2007), houve um ressuscitar de estudos sobre a relação entre inteligência e religiosidade. Dois desses estudos fizeram uso de grandes amostras em nível agregado, demonstrando uma relação negativa entre escores de inteligência nacional com escores de inteligência nacional média.

Embora o efeito da inteligência sobre religiosidade seja bem estabelecido, há evidências conflitantes sobre o processo subjacente a esse efeito e, em particular, o papel da educação nesse processo. A hipótese mais plausível é que educação baliza, parcial ou integralmente, o efeito da inteligência sobre a religiosidade, ou seja, que pessoas inteligentes são menos religiosas porque obtém mais educação. Neste caso, a razão para este possível processo mediador é mais do que clara: inteligência tem um forte efeito sobre o desempenho educacional e, por sua vez, educação fornece às pessoas oportunidades para estas buscarem alternativas racionais ao dogma religioso.

Entretanto, o papel da educação, neste processo, não tem sido muito claro, pois, há estudos revelando certa inconsistência em relação à ideia de que educação balize o efeito negativo da inteligência sobre religiosidade. Na verdade, esses estudos sugerem que educação reduz o efeito líquido negativo da inteligência sobre religiosidade porque, em geral, pessoas mais inteligentes obtém mais educação.

Assim considerando, se a vivência religiosa realmente modera o efeito da educação sobre a religiosidade, é provável que, desde que inteligência tenha um forte efeito positivo sobre educação, o efeito observado da inteligência sobre religiosidade também dependerá da vivência religiosa: será mais negativo quando a vivência religiosa for mais fraca do que quando ela for forte.

Com o propósito de resolver esta interação complexa entre inteligência, educação e religiosidade, Ganzach, Ellis e Gotlibovski (2013) 
manipularam e correlacionaram escores de religiosidade, vivência religiosa, inteligência, educação, idade, sexo dos participantes e etnia, encontrando, como resultado, que educação não baliza o efeito da inteligência sobre religiosidade. Porém, esses mesmos dados não deixam de sugerir que educação tem um efeito positivo sobre religiosidade quando a vivência religiosa é forte e um efeito negativo quando a mesma é fraca. Além disso, desde que inteligência tem um efeito positivo sobre educação, o efeito negativo da inteligência sobre religiosidade é mais forte quando a vivência religiosa é elevada do que quando ela é fraca (ver também, Bertsch, $\&$ Pesta, 2009; Nyborg, 2009; Pesta, MacDaniel, \& Bertsch, 2010).

No global, os resultados atestam claramente o seguinte: para aqueles originados de ambientes fortemente religiosos, educação tem um efeito positivo sobre a religiosidade, o qual conduz a um efeito indireto positivo da inteligência, mesmo embora o efeito direto da inteligência tenha sido negativo. Por outro lado, educação tem um efeito negativo para aqueles oriundos de ambientes seculares. Como resultado, inteligência, para estas pessoas, não tem apenas um efeito direto negativo, mas, também, um direito indireto negativo, mediado pela educação. Logo, o papel de influência, ou mediação, da educação, ou da inteligência, sobre a religiosidade depende, em muito, do background religioso ou da vivência religiosa da população investigada.

\section{Qual a Relação entre Inteligência e Ateísmo?}

Dawkins (2007) sugere que não é inteligente acreditar na existência de Deus. Para investigar essa afirmação dolorida, Lynn, Harvey e Nyborg publicaram um trabalho na revista Intelligence, em 2009, investigando se inteligência média prediz as taxas de ateísmo em 130 nações. Eles examinaram: (a) a evidência para a afirmação, isto é, se há uma relação negativa entre inteligência e crença religiosa; (b) se essa relação negativa é uma diferença na inteligência geral - $\mathrm{g}$ e (c) se há uma relação negativa entre inteligência e crença religiosa entre nações.
Em relação à primeira, existem vários estudos relatando correlações negativas entre inteligência e crença religiosa. Por exemplo, num dado estudo, pesquisadores perguntaram "Em que grau você é uma pessoa religiosa?", com respostas codificadas da seguinte forma: "não religioso", "levemente religioso", "moderadamente religioso" e "muito religioso". Os resultados mostraram que os "não religiosos" tiveram o QI mais elevado (103), seguido, em ordem decrescente, pelos outros três grupos, que pontuaram da seguinte forma, respectivamente: (99), (98) e (97). A relação entre QI e crença religiosa foi altamente significante. Também há estudos mostrando uma menor porcentagem de pessoas da elite intelectual mantendo crenças religiosas quando comparadas à população em geral. Isso foi revelado a partir de um levantamento indicando que apenas $39 \%$ dos eminentes cientistas e sábios norte-americanos afirmaram acreditar em Deus, numa amplitude que variou de $48 \%$ entre historiadores a $24 \%$ entre psicólogos.

Referente à associação negativa entre crença religiosa e inteligência geral, dados obtidos de um estudo longitudinal, que amostrou $15 \mathrm{mi}-$ lhões de adolescentes americanos na idade de 12 a 17 anos, revelaram que os ateístas pontuavam 6 pontos de QI a mais do que grupos combinados de sujeitos que professavam uma ou outra religião. A diferença na inteligência entre ateístas e religiosos foi significativa, mesmo sem usar dados ponderados (Lewis, Ritchie, \& Bates, 2011; ver também, Reeve, 2009 e Reeve \& Basalik, 2011).

Por sua vez, para verificar a relação entre inteligência e crenças religiosas entre as nações, pesquisadores consideraram, de 137 nações, os QIs obtidos em cada nação e os indicadores de crenças em Deus, o que representou, aproximadamente, uma verificação em $95 \%$ da população mundial. Os dados indicaram que, em apenas $17 \%$ dos países (23 de 137), a proporção da população que não acredita em Deus situa-se acima de $20 \%$. Estes países são, virtualmente, aqueles que têm QI mais elevado. A correlação entre QI nacional e descrença religiosa variou de +0.16 (populações com QI de 64 a 86), $+0,60$ (popula- 
ções com QI de 64 a 108) e $+0,54$ (populações com QI de 87 a 108). Neste grupo, em particular, $20 \%$ da população, não acreditam em Deus (ver também, Kanazawa, 2009, 2010; Lynn \& Vanhanen, 2012).

Logo, na descrença religiosa, a maior parte da variação está entre as nações com QI mais alto.

\section{Referências}

Bertsch, S., \& Pesta, B. J. (2009). The Wonderlic Personnel Test and elementary cognitive tasks as predictors of religious sectarianism, scriptural acceptance and religious questioning. Intelligence, 37, 231-237.

Dawkins, R. (2007). Deus, um delirio (F. Ravagnani, Trad.). São Paulo, SP: Companhia das Letras.

Dutton, E. (2013). A Problematic Proxy? On Meisenberg, Rindermann, Patel and Woodley's (2012) analysis of the relationship between religiosity and intelligence within countries. Temas em Psicologia, 21(2), 525-527. DOI: 10.9788/ TP2013.2-18.

Ganzach, Y., Ellis, S., \& Gotlibovski, C. (2013). On intelligence education and regiligious beliefs. Intelligence, 41, 121-128.

Kanazawa, S. (2009). IQ and the values of nations. Journal of Biosocial Science, 41, 537-556.

Kanazawa, S. (2010). Why liberals and atheists are more intelligent. Social Psychology Quarterly, 73, 33-57.

Leal, L. N. (2011, 24 ago.). Proporção de católicos tem baixa recorde. O Estado de São Paulo, p. A19.

Lewis, G., Ritchie, S. J., \& Bates, T. C. (2011). The relationship between intelligence and multiple domains of religious belief: Evidence from a large adult US sample. Intelligence, 39, 468-472.
Lynn, R., Harvey, J., \& Nyborg, H. (2009). Average intelligence predicts atheism rates across 137 nations. Intelligence, 37, 11-15.

Lynn, R., \& Vanhanen, T. (2012). Intelligence: A unifying construct for the Social Science. London: Ulster Institute for Social Research.

Meisenberg, G. (2013). A reply to Dutton's (2013) comment. Temas em Psicologia, 21(2), 529-530. doi: DOI: 10.9788/TP2013.2-19.

Meisenberg, G., Rindermann, H., Patel, H., \& Woodley, M. (2012). Is it smart to believe in God? The relationship of religiosity with education and intelligence. Temas em Psicologia, 20(1), 101-120.

Nyborg, H. (2009). The intelligence-religiosity nexus: A representative study of white adolescent Americans. Intelligence, 37, 81-93.

Pesta, B. J., MacDaniel, M. A., \& Bertsch, S. (2010). Toward an index of well-being for the fifty U.S. states. Intelligence, 38, 160-168.

Reeve, C. (2009). Expanding the g-nexus: Further evidence regarding the relations among national IQ, religiosity and national health outcomes. Intelligence, 37, 495-505.

Reeve, C., \& Basalik, D. (2011). A state level investigation of the associations among intellectual capital, religiosity and reproductive health. Intelligence, 39, 64-73. 